\title{
Porphyria due to ALA dehydratase deficiency
}

INSERM

\section{Source}

INSERM. (1999). Orphanet: an online rare disease and orphan drug data base. Porphyria due to ALA dehydratase deficiency. ORPHA:100924

Porphyria of doss or deficiency of delta-aminolevulinic acid dehydratase (DALAD) is an extremely rare form of acute hepatic porphyria (see this term) characterized by neurovisceral attacks without cutaneous manifestations. 